\title{
Application of Heuristic Optimization for the Selection of Parameters of the Generation System and Reactive Power Consumption of Wind Farms
}

\author{
Michalina Gryniewicz-Jaworska1* \\ 1 Department of Computer Science, Lublin University of Technology, ul. Nadbystrzycka 36B, 20-618 Lublin, \\ Poland \\ * Corresponding author's e-mail: m.jaworska@pollub.pl
}

\begin{abstract}
The cooperation of wind farms with the power system requires that they meet the requirements related to reactive power management. In practice, it concerns both generation and production of this power in accordance with the requirements of network operators and EU Regulation 2016/631. The regulatory capacity of wind turbine generators is not sufficient to meet these requirements, in particular for farms connected to the power system via a $110 \mathrm{kV}$ cable line with a length of several dozen kilometers. It is required to use various additional devices - fixed or variable shunt reactor, capacitor batteries, static VAR compensators (SVC). In the article, a compensation quality indicator was defined, by means of which it is possible to assess and select the optimal set of devices supporting the farm's generation and reactive power consumption capabilities. Due to the application of multicriteria optimization, this indicator unifies both the technical effectiveness of individual systems and the economies of their use.
\end{abstract}

Keywords: reactive power compensation, heuristics, wind farms

\section{INTRODUCTION}

The dynamic development of wind energy, expressed both in the growing number of wind farm connections (WF) to the power system as well as in the growing generation capacity of the connected farms, makes the issues related to voltage and reactive power regulation more and more important. The extensive structure of the wind farm network including wind turbines, medium voltage cable network, HV/MV transformers and static reactive power sources requires taking into account both specific voltage parameters at the point of connection of the farm to the power grid and the internal parameters of the farm network resulting from the technical requirements of the installed devices. It is difficult to realistically assess the capacity of wind power units that may operate in the Polish power system in the years 2020-2030. Currently this power has reached $6000 \mathrm{MW}$. The future interest of investors in wind energy may be regulated by legal solutions concerning support systems as well as administrative and statutory restrictions $[11,12]$.

\section{Generation and reactive power off-take by a wind farm}

The documents specifying the requirements for generating units operating in the power system $[2,3]$, as well as works [9] specify the requirements for wind farms regarding participation in voltage regulation through the generation or off-take of reactive power $[1,10]$. The participation is based on the fact that for voltages (in the farm connection node defined as PCC - Point of Common Coupling) in the range from 105 to $120 \mathrm{kV}$, the farm may show zero reactive power flow $[8,9]$. For low voltages (below $100 \mathrm{kV}$ ) the farm should generate maximum reactive power, and for voltages above $125 \mathrm{kV}$ the farm should draw maximum reactive power. Considering the 
simplified scheme of the internal wind farm network (Fig. 1), it is possible to distinguish between sources and off-take of reactive power, which in turn determines the balance of reactive power at the connection point (PCC) and whether the requirements of EU 2016/631 can be met. European Union Regulation No. 631 of 2016 [4], introduced several requirements for generating sources connected to the grid. Wind farms with a capacity of more than $50 \mathrm{MW}$ are classified as type C and D sources, and besides, the legislator classifies them as Energy Park Modules (PPM) with specific requirements for the connection point to the SEE (for the capacity of more than $50 \mathrm{MW}$ it is usually a $110 \mathrm{kV}$ network). Part of these requirements concerning the capacity to generate and absorb reactive power by PPM (understood as a whole, i. e. $110 \mathrm{kV}$ internal line, $110 / \mathrm{MV}$ transformer, MV cable network, wind turbine generators with MV/LV converter systems).

Among many problems of wind farm construction and their integration with the power system, the aspect of the share of wind farms in the global power system reactive power management and its importance for maintaining appropriate voltage levels and achieving sustainable voltage stability should be noted. When considering the production and consumption of reactive power by a wind farm, it should be borne in mind that the following equipment and installations are involved in this process:

- Wind power generators with $\mathrm{Q}(\mathrm{P})$ characteristics shaped by the manufacturer, most often in response to the expectations and requirements of network operators;

- medium voltage (MV) cables which are both a source of reactive power (capacity) and its receiver (longitudinal losses on reactance under load conditions);
- MV-side capacitor banks with step-adjustable capacitance installed when it is necessary to increase the reactive power generation capacity of the farm;

- $\mathrm{HV} / \mathrm{MV}$ transformer being a reactive power receiver;

- HV cable connecting the farm switchgear to the point of connection of the farm to the network (PCC) showing significantly high capacity as well as longitudinal losses on reactance;

- shunt reactor connected to the HV network providing compensation of the HV cable capacity depending on the network conditions and the operating status of the farm; various solutions are possible within the scope of regulating this shunt reactor- from a device with constant susceptance to a system with smooth regulation (SVC, STATCOM);

- supplementary regulation shunt reactor connected on the MV side of the farm.

The efficiency and possibilities of reactive power generation (or consumption) by a wind farm are not based only on the policy of their owners. They are imposed on network operators, which in turn are forced to apply specific policy towards investors and farm owners by defining specific technical standards of the European Union, responsibility for the security of the power system and a commercial view on the costs of distribution of energy produced by WF.

\section{Application of the Cuckoo Search Algorithm, with regard to the selection of compensation system parameters}

Currently, heuristic algorithms are used to solve optimization issues, which easily adapt to the constraints, regardless of the number of

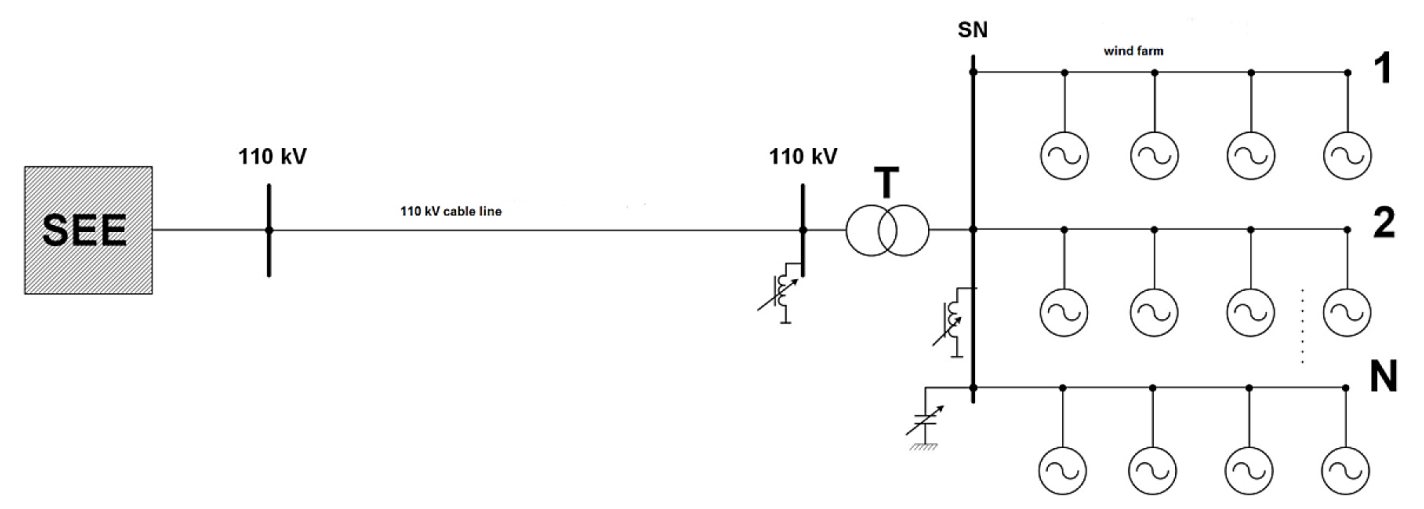

Fig. 1. Scheme of the $110 / 30 \mathrm{kV}$ internal grid of a wind farm (reactive power requirements apply to the point of connection to the $110 \mathrm{kV}$ grid - PCC) [5] 
variables and size of solution space. In recent years, swarm algorithms based on swarm intelligence have been used to solve the above-mentioned issues, the principles of which have been taken from observation of nature. The inspiration of these algorithms comes from observing biological systems such as bee swarms, ant colonies, schools of fish and flocks of birds. The most commonly used swarm algorithms are the Cuckoo Search Algorithm (CS), the Firefly Algorithm (FA), and the Particle Swarm Optimization algorithm (PSO). To solve the optimization task, the "Cuckoo Search CS" algorithm, whose authors are Xin-she Yang and Suash Deb, was used. The CS algorithm is one of the newer heuristic algorithms.

Below is a diagram of the CS algorithm:

\section{Begin}

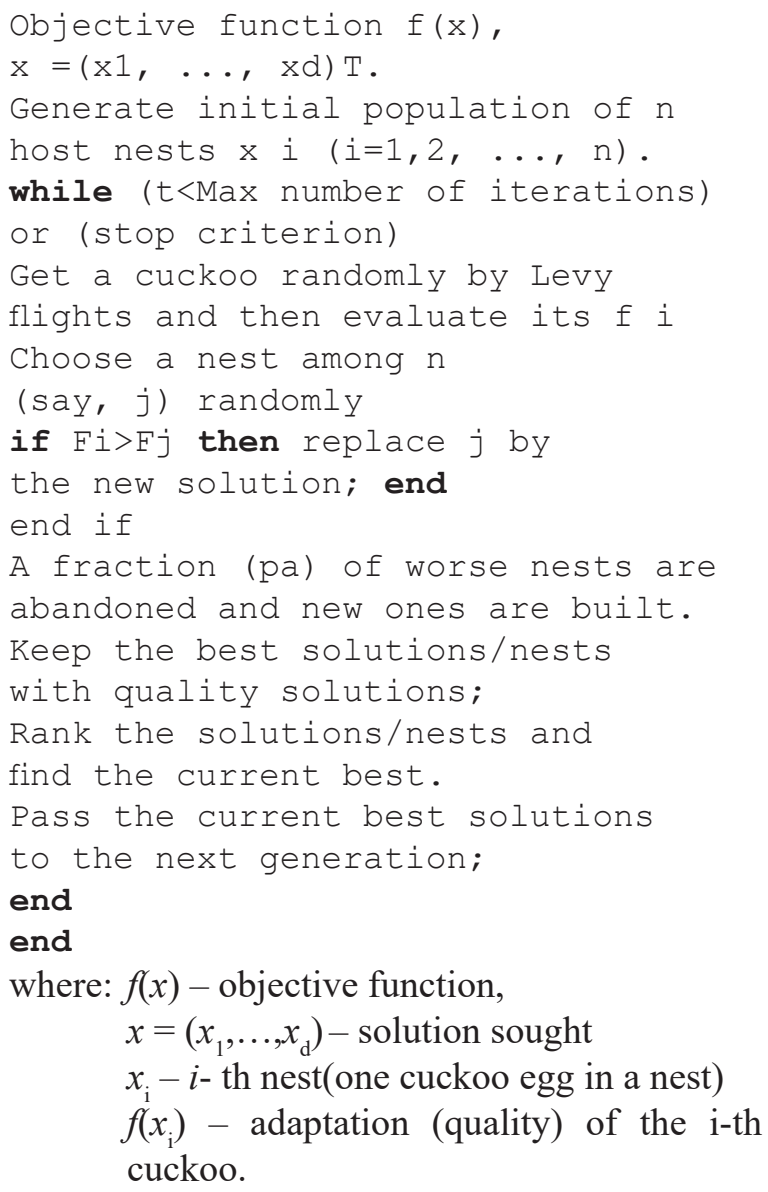

The authors use the Levy flight algorithm to select the next nest by cuckoo:

$$
x_{i}^{m}=x_{i}^{m-1}+\alpha_{c s}^{L e v y}
$$

where: $m$ - step number, i.e. the next iteration, $x_{i}^{m}$ - the solution obtained in the m-th step for the i-th cuckoo, $\alpha_{c s}-$ scale factor, the value of which depends on the size of the problem,

Levy - the length of the step, determined by Levy's probability distribution.

The Levy distribution is a continuous probability distribution for non-negative random variables. It is one of the few distributions that is stable and has a probability density function expressed analytically 12 .

\section{Formulation of assumptions for calculations}

Implementation of the CS algorithm seems quite simple, as long as determining the objective function in the i-th step of calculations is considered a trivial task. In order to determine the three basic values associated with reactive power transmission $-Q_{\text {min_PCC }(p)}, Q_{\text {max_PCC }(p)}, Q_{0 \_ \text {PCC }(l)}$. It is necessary to perform a flow calculation for each hour for the model shown in Figure 2. The original result of the flow analysis, which is de facto a solution of the nonlinear equation system, is not the distribution of power, but a nodal voltage vector for all network nodes. For networks with $\mathrm{N}$ nodes it is a vector with a form:

$$
\hat{U}=\left[\hat{U}_{1} \ldots . \hat{U}_{i} \ldots . \hat{U}_{N}\right]
$$

Based on the knowledge of the voltage vector in complex form (phasors), it is possible to determine all the quantities characterizing the flow in the network - currents, active power and reactive power. Below are formulas on the basis of which it is possible to determine the power flowing into the system from this line. The sign ${ }^{\wedge}$ on the size symbol means that it is a complex size:

- longitudinal admittance of the line

$$
\hat{Y}_{b(k-l)}=\frac{1}{R_{b(k-l)}+\mathrm{j} X_{b(k-l)}}
$$

- current flowing along the longitudinal part of the line model

$$
\hat{I}_{k-l}=\left(\hat{U}_{k}-\hat{U}_{l}\right) \cdot \hat{Y}_{b(k-l)}
$$

- total line current flowing from the node 1

$$
\hat{I}_{b}=\left(\hat{U}_{k}-\hat{U}_{l}\right) \cdot \hat{Y}_{b(k-l)}+\hat{U}_{l} \cdot \mathrm{j} \frac{B_{b(k-l)}}{2}
$$

- apparent power flowing from nodel (the sign * means conjugate)

$$
\hat{S}_{b}=\hat{U}_{l} \cdot \hat{I}_{b}^{*}
$$




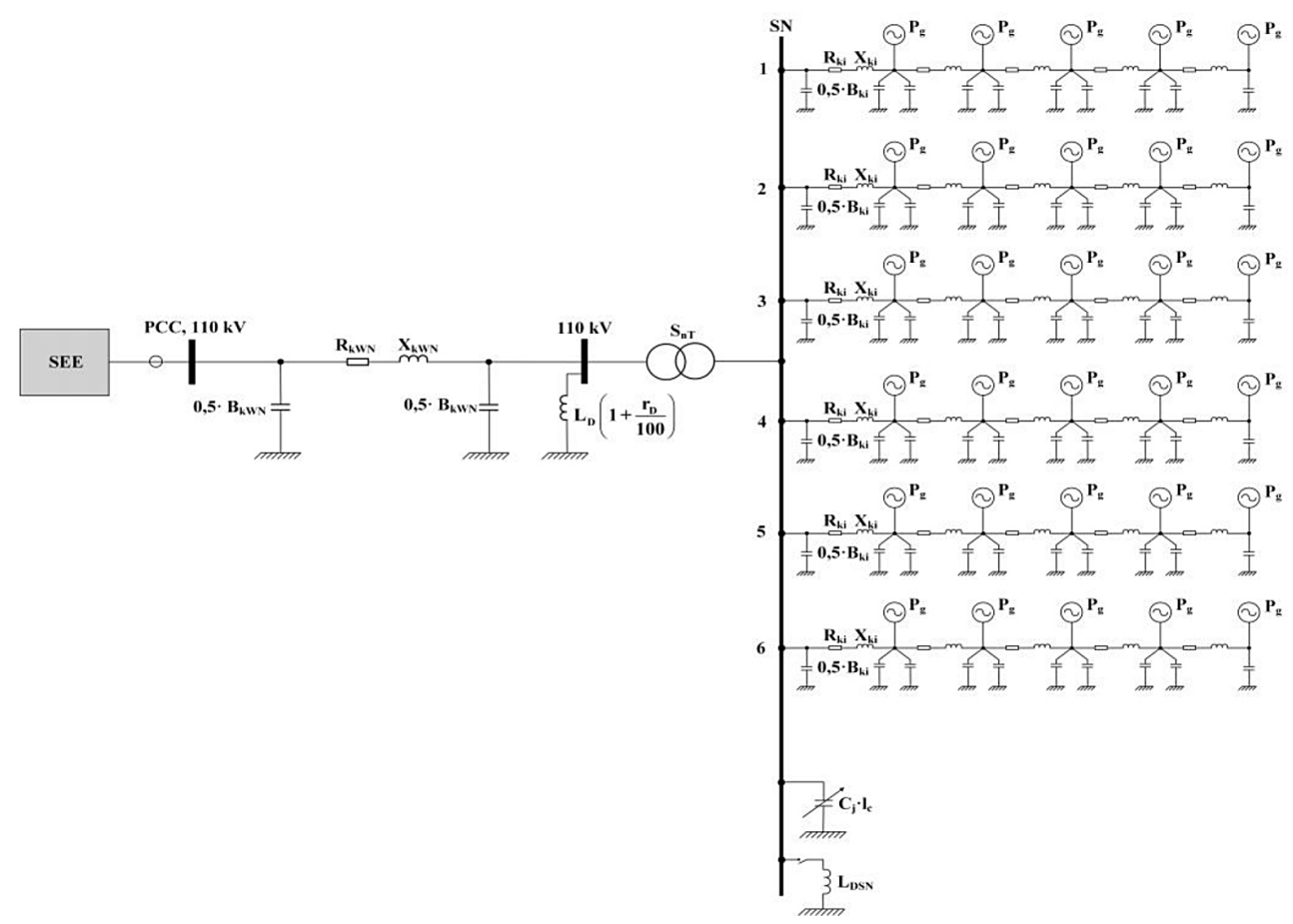

Fig. 2. Wind farm network model considered in heuristic optimization calculations

- active power flowing from node 1 (real part of apparent power)

$$
P_{b}=\operatorname{Re}\left(\hat{U}_{k} \cdot \hat{I}_{b}^{*}\right)
$$

- reactive power flowing from node 1 (imaginary part of apparent power)

$$
Q_{b}=\operatorname{Im}\left(\hat{U}_{k} \cdot \hat{I}_{b}^{*}\right)
$$

Decision variable vector

$$
\mathbf{x}=\left[r_{D}, l_{C}, L_{D S N}\right]
$$

consists of three elements: HV shunt reactor compensation degree (calculations start from $r_{D}=0 \%$ ), number of capacitor banks on the MV side (calculations start from the value of $l_{\mathrm{C}}=0$ ), the inductance of the shunt reactor on the MV side (calculations start from $L_{D S N}=1000 \mathrm{mH}$, zero value would interfere with the calculation process). Calculations are carried out for annual periods in order to achieve the minimum value of the objective function. In the next step, the values of the decision variable vector elements change according to the principles of the heuristic algorithm under consideration, in this case, CS. The objective function of the $\mathrm{W}_{\mathrm{Q}}$ wind farm reactive power compensation system should include three elements: farm readiness to meet the requirements in terms of capacity to generate and consume this power, farm capabilities in the scope of limiting reactive power flow to the network in conditions of zero active power generation and limiting the cost of the compensation system.

\section{Organization of the calculation process}

The organization of the calculation process is carried out in two loops; the internal (counter 1) includes the subsequent hours of the year (total 8760), the external (counter i) counter of the optimization process (up to the set value $i_{\text {max }}$ ). Calculation control is carried out at the Matlab level. Heuristic optimization according to the CS algorithm is also implemented according to the application included in this program. These calculations are essentially autonomous (they relate to the three components of the vector $\mathbf{x}$. The flow calculations must be carried out by an external calculation module. Unfortunately, full flow calculations carried out for the network are essentially iterative calculations, triggered for each hour of the year cause that a single iteration to determine the value of the objective function $\mathrm{W}_{\mathrm{Q}}$ is implemented for nearly $30 \mathrm{~min}$. Therefore, using the fact of the radial structure of the network, simplified flow calculations were used, achieving a single iteration time of $1 \mathrm{~min}$. Thus, the course of calculations according to the optimization algorithm according to the CS method lasts about 2 hours. 


\section{RESULTS OF OPTIMIZATION CALCULATIONS}

Testing the heuristic method proposed for the problem being solved is checking the number of iterations after which the solution stabilizes and can be considered optimal. It is advisable to repeat the calculation multiple times to check the repeatability of the results. The calculation of the optimal selection of reactive power compensation system parameters using the CS algorithm was repeated several times. Based on the results obtained, it can be concluded that it is characterized by a small dispersion, in the case of capacitor banks, 16 members were obtained.

It can also be seen that the use of a shunt reactor on the MV side (average inductance $445 \mathrm{mH}$, power 6.28 Mvar) improves the value of the quality index $\mathrm{W} \mathrm{Q}=0.56777$, compared to the value obtained without its use $\left(\mathrm{W}_{\mathrm{Q}}=0.625\right)$. However, the parameters considered optimal do not completely eliminate the generated or consumed power deficits and the zero reactive power flow in standstill conditions. Their "optimality" is determined by costs, because striving for ideal compensation would increase them and worsen the value of the multi-criteria $\mathrm{W}_{\mathrm{Q}}$ indicator.

The following figures (Fig. 3a, 3b) show the course of the calculation process implemented according to the CS algorithm. The stabilization of the objective function and the values of decision variables after approx. 70 iterations are visible. The set values come in a variety of ways, which is a natural consequence of the elements of probability that occur in all heuristic algorithms, including CS. Despite this, the computational efficiency of the algorithm, even with a small number of iterations, does not raise doubts as to the possibility of formulating a method for optimizing the generation system and reactive power consumption of a wind farm.

a)

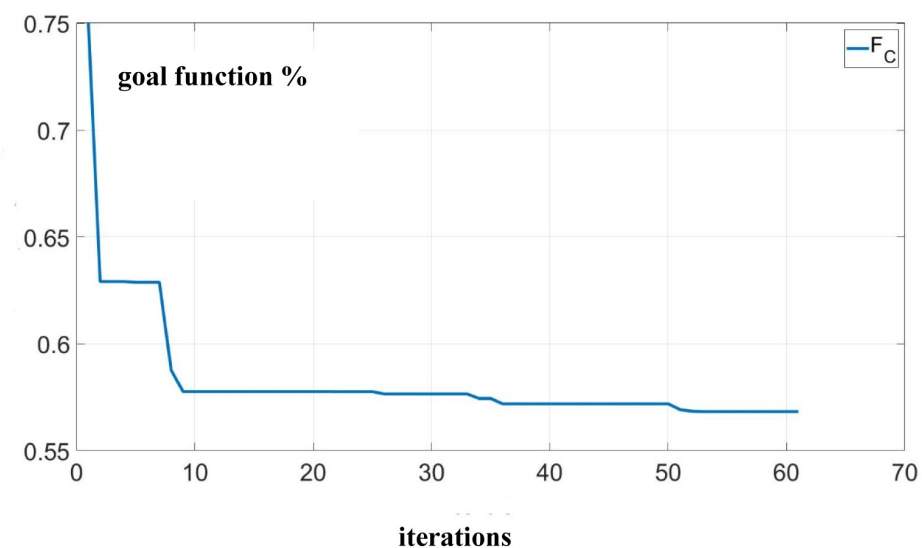

b)

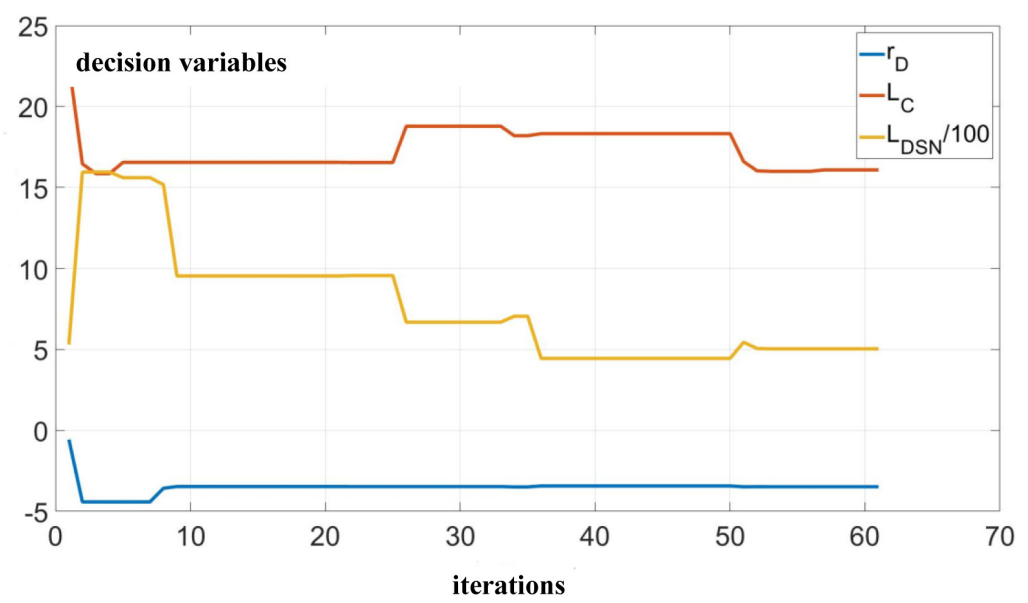

Fig. 3. The course of the calculation process, test No. 1 a) objective function $\mathrm{W}_{\mathrm{Q}}$ b) decision variables decyzyjne $r_{\mathrm{D}}, L_{C}, L_{\mathrm{DSN}}$ 


\section{CONCLUSIONS}

Based on the research, it has been shown that the best values are achieved by the Q quality compensation index for a properly selected reactor with a constant inductance (FSR) on the $110 \mathrm{kV}$ side with a capacitor bank on the farm $30 \mathrm{kV}$ and optionally an additional reactor on the MV side of the farm. The results obtained for a $50 \mathrm{~km}$ long cable line using the heuristic optimization method and an accurate flow model confirmed the correctness of the analyzes carried out using the CS method, demonstrating that the use of an additional cable gland on the MV side of the farm $\left(\mathrm{FSR}_{\mathrm{MV}}\right)$ further improves the quality of compensation, while maintaining an acceptable level of investment costs.

\section{REFERENCES}

1. Instrukcja Ruchu i Eksploatacji Sieci Dystrybucyjnej, [dostęp 08 lipca 2018]. Dostępny w World Wide Web:https://pgedystrybucja.pl/DlaKlienta/IRiESD

2. Instrukcja Ruchu i Eksploatacji Sieci Przesyłowej PSE S.A. [dostęp 08 lipca 2018]. Dostępny w World Wide Web: http://www.pse.pl/.

3. Kacejko P., Pijarski P., Generation level matching to the transmission capability of overhead lines, $\mathrm{nr}$ 1/14, ActaEnergetica, 2013, vol. 1. pp. 43

4. Ogryczak W., Wielokryterialna optymalizacja liniowa i dyskretna, Wydawnictwo Uniwersytetu Warszawskiego, Warszawa, 1997.
5. Pijarski P., Kacejko P., Wancerz M., GryniewiczJaworska M., Układ sterowania mocą bierną farmy wiatrowej wykorzystujący możliwości regulacyjne przekształtników, dławika zaczepowego oraz pojemność kabla zasilającego farmę, nr 8, Przegląd Elektrotechniczny, 2016, vol. 92. pp. 44

6. Pijarski P., Wydra M., Kacejko P., Optimal control of wind power generation, $\mathrm{nr}$ 1, Advances in Science and Technology Research Journal, 2018, vol. 12. pp. 15

7. Polityka Energetyczna Polski do 2040 r., Ministerstwo Energii, Warszawa 2018.

8. Polityka Energetyczna Polski do 2040 r., wersja 2.1, 08.11.2019 r. Ministerstwo Energii.

9. Sarkar M.N.I., Meegahapola G., Datta M. Reactive Power Management in Renewable Rich Power Grids: A Review of Grid-Codes, Renewable Generators, Support Devices, Control Strategies and Optimization Algorithms. Reactive Power Management in Renewable Rich Power Grids, 2018.

10. Tanvir A.A., Merabet A., Beuanane R. Real-Time Control of Active and Reactive Power for Doubly Fed Induction Generator (DFIG)-Based Wind Energy Conversion System, Energies, 2015.

11. Tomaszewski J. Cuckoo Search, 2016. [dostęp 07 lipca 2018]. Dostępny w World Wide Web: http:// wikizmsi.zut.edu.pl/uploads/b/b5/OzWSI_I_S1_ c10.pdf

12. Ustawa z dnia 7 czerwca 2018 r. o zmianie ustawy o odnawialnych źródłach energii oraz niektórych innych ustaw, Poz. 1276, [dostęp 05 lipca 2018]. Dostępny w World Wide Web:http:// prawo.sejm.gov.pl/isap.nsf/download.xsp/ WDU20180001276/O/D20181276.pdf 